\title{
Investigation of laminar plasma remelting/cladding processing
}

\author{
Wei Ma*, Qunxing Fei, Wenxia Pan, Chengkang Wu \\ Institute of Mechanics, Chinese Academy of Sciences, \\ Beijing 100080, China
}

Received 18 January 2005; received in revised form 16 May 2005; accepted 16 May 2005

Available online 24 June 2005

\begin{abstract}
Investigation of remelting and cladding processing with laminar plasma jets on several metals has been conducted looking for possible development of a new surface modification technique. The remelting tests illustrated that the new method could evidently improve the material microstructure and properties of cast iron. The cladding was done with $\mathrm{Al}_{2} \mathrm{O}_{3}$ ceramic powder on stainless steel. The energy dispersive spectra (EDS) analysis was used to determine the distribution of the major cladding element in the plasma-processed layers, for which the microstructure observations and hardness measurements were also performed.
\end{abstract}

(C) 2005 Elsevier B.V. All rights reserved.

Keywords: Laminar plasma jets; Remelting; Cladding; Microstructure

\section{Introduction}

Laser processing has been widely applied in material surface engineering because of its concentrated energy output and good treatment results [1-4]. But, research [5] showed that the thermal efficiency of the laser beams is quite low compared to the plasma arcs. Moreover, the operating costs of laser equipment are generally quite high. Hence, it may be advantageous to develop novel plasma techniques with high reliability, high thermal efficiency and low operation costs. The laminar plasma jet has some advantages

\footnotetext{
* Corresponding author. Tel.: +86 1082622614 ; fax: +8610 82622614 .

E-mail address: watwm@imech.ac.cn (W. Ma).
}

[6,7]: (i) being produced conveniently at relatively low input powers; (ii) reduced entrainment of impurities and ambient gases into the plasma flow and the molten pool, (iii) low temperature gradient in the axial direction, (iv) low operating expenses and (v) reducing environmental pollution considerably. Hence, it is possible that the laminar plasma technique may be developed into a helpful processing tool in surface engineering.

The main purpose of the current study was to explore surface processing methods with the laminar plasma jet and to find their potential applications in metal surface modification. Comparative remelting and cladding tests for three metals with large differences in material thermal properties were carried out. The results demonstrate that the laminar plasma 
processing is a promising technique, which can be effectively used in the remelting and cladding surface modification of the metals under certain conditions.

\section{Experimental details}

The sample materials are commercial $1 \mathrm{Cr} 18 \mathrm{Ni} 9 \mathrm{Ti}$ stainless steel, HT 100 cast iron and Al-Si alloy, of which the thermal conductivities and melting points are, respectively, 28,41 and $168 \mathrm{~W} / \mathrm{m} \mathrm{K}$ and 1400,1130 and $580{ }^{\circ} \mathrm{C}$. The corresponding sample dimensions are $80 \times 20 \times 3,120 \times 80 \times 20$, and $80 \times 40 \times 10 \mathrm{~mm}$. The added materials used for the cladding research are $\mathrm{Al}_{2} \mathrm{O}_{3}$ and $\mathrm{SiC}$ ceramic powders with particle sizes $+25-75$ and $+20-40 \mu \mathrm{m}$, respectively. The processing parameters were plasma jet input power $5-7 \mathrm{~kW}$, heating distance $5-10 \mathrm{~mm}$, working gas rates 3-6 L/min, and substrate moving velocities $3-5 \mathrm{~mm} / \mathrm{s}$. The substrates preheat temperature and the powder feed rates were $350-420{ }^{\circ} \mathrm{C}$ and $2-3 \mathrm{~g} / \mathrm{min}$, respectively, in the cladding tests. The plasma working gas and carrier gas were both argon. Before testing the sample surfaces were rubbed with $100-300 \mu \mathrm{m}$ sand paper to increase surface roughness.

The experiments include remelting without powder feeding and cladding with powder feeding for the metals. The remelting tests were performed to demonstrate that under the particular processing conditions the technique is adaptable to cast iron. The cladding tests were carried out on the stainless steel with the $\mathrm{Al}_{2} \mathrm{O}_{3}$ powder and the $\mathrm{Al}-\mathrm{Si}$ alloy with the $\mathrm{SiC}$ powder to illustrate the processing feasibility. Metallographic samples for the microscopic observations were prepared following standard mechanical polishing procedure.

Morphologies of the heat-affected zone and the clad layer were examined by using optical microscope (OM) and scanning electron microscope (SEM) equipped with an energy dispersive spectrometer (EDS). The relative EDS analysis of the element distribution of $\mathrm{Al}$ and $\mathrm{Si}$ in the molten pools was performed for the evaluation of the cladding effects. Hardness along the depth direction of the plasmaprocessed layers was measured by using a Vickers micro-hardness tester with a test load of $200 \mathrm{~g}$ and an acting time of $10 \mathrm{~s}$.

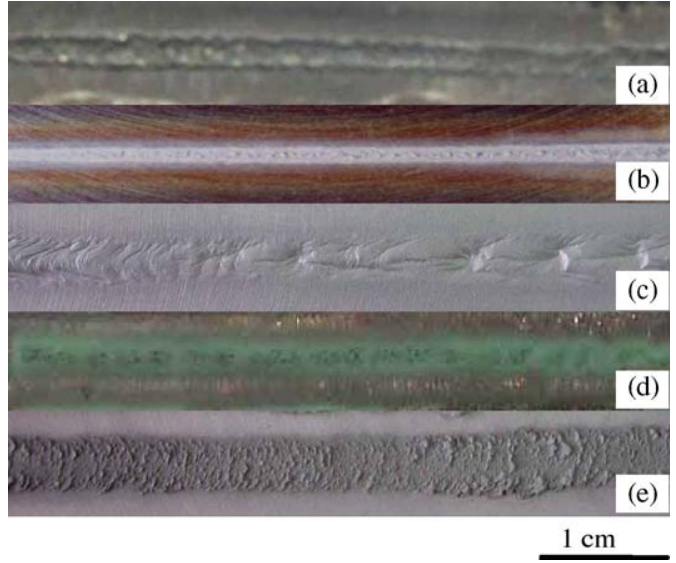

Fig. 1. Appearance of the remelting tracks on the stainless steel surface (a); cast iron surface (b) and Al-Si alloy surface (c). Appearance of the cladding tracks on the stainless steel surface (d) and Al-Si alloy surface (e).

\section{Results and discussion}

\subsection{Remelting tests}

The remelting test results show that under specific processing conditions the laminar plasma jets can produce evident heat treatment effects on the metal surfaces (Fig. 1(a)-(c)). The tracks for each metal exhibited quite different features, such as, a deep groove shape for the stainless steel (Fig. 1(a)), a sufficiently planar surface track for the cast iron (Fig. 1(b)) and a wide melting track with some dimples for the Al-Si alloy (Fig. 1(c)). Apparently, the features are related to the material thermal properties.

Metal remelting processing is a quick heating and cooling procedure with accompanying material phase transformation under rapid solidification conditions. In the laser processing, considerable modeling studies deal with the material microstructure evolution and the thermal transfer mechanisms of the molten pool, e.g. [1]. Due to the action of plasma gas pressures on the matter in the molten pool, the plasma processing deals with even more complicated phenomena than that of the laser method. Hence, there is still a significant lack in the related numerical modeling studies. Usually in the laser or plasma remelting processes, the liquid/solid interface advances with a velocity approaching the substrate motion velocity, and the solidification rates are somewhat less than that 
of the substrate velocity [8]. In the present study the solidification rates are less than $4 \mathrm{~mm} / \mathrm{s}$ for the cast iron and less than $3 \mathrm{~mm} / \mathrm{s}$ for the stainless steel and the $\mathrm{Al}-\mathrm{Si}$ alloy. The diameters of the melting pools were about $4 \mathrm{~mm}$ on the stainless steel and cast iron substrates and $7 \mathrm{~mm}$ on the $\mathrm{Al}-\mathrm{Si}$ alloy substrates. So the solidification time was about 1-2 s. During the remelting process, a high temperature gas boundary layer produced by plasma gas spread on the pool surface, which considerably obstructed the heat convection between the melting matter and the air. Thus, the heat quantity of the melting pool was principally transferred through the solid phase by heat conduction mechanisms. Moreover, in such a short solidification interval the temperature gradients in the stainless steel and cast iron substrates were on a same order and their influence on the heat conduction can be omitted. Therefore, the thermal conductivities of the solid materials are the key factors in the heat diffusion mechanisms of the melting pool matters.

With the low heat conductivity of the stainless steel, less heat energy was lost in the solidifying time, so the liquid phase matter in the melting pool could acquire sufficient thermal energy and reach quite high temperatures. Thus, the viscosity of the liquid phase sharply decreases, and under the action of the plasma gas pressures, some liquid matter was blown away to both sides of the remelting tracks and formed the profiles with a thin transition layer and an uneven surface (Fig. 2(a)). The cast iron has good heat conductivity and high melting point. Heat can be transferred more rapidly by solid phase with the heat conducting rate 1.5 times that of the stainless steel. Thus, the liquid phase matter in the melting pool could remain at lower temperature and higher viscosity so that it can sustain the action of the plasma gas pressure. At the same time, heat transferred into the solid phase promoted the development of the large heat-affected zone (Fig. 2(b)). The microscopic observation illustrated that the martensite phases and sheet graphite morphologies have developed in the melting pool and cementite, ledeburite and discrete graphited phases have grown on the track surface. The Al-Si alloy has the highest heat conductivity and lowest melting point, only about one-third of the heat dissipated by the stainless steel molten was required to remelt it and the heat quantity was rapidly transferred through the solid phase with a

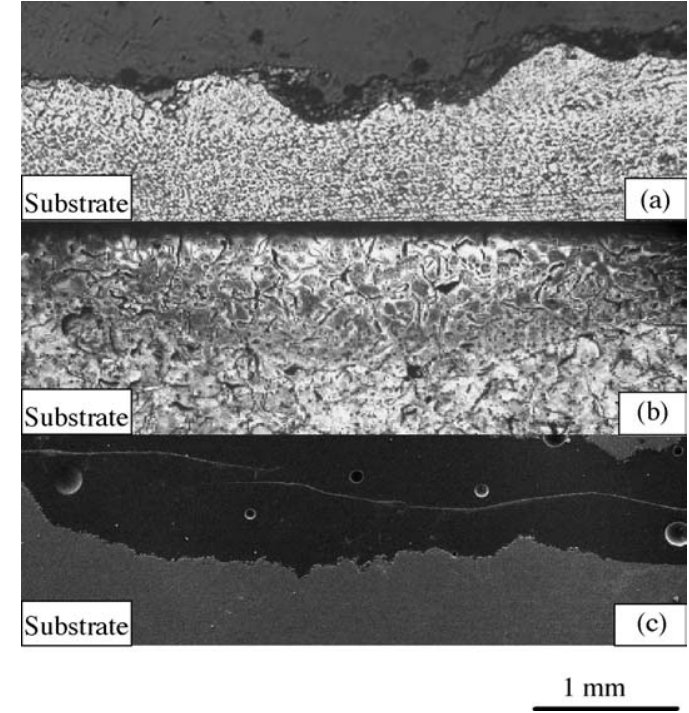

Fig. 2. The microscopic observations of the cross-section of the remelting treatment of the stainless steel sample (a); cast iron sample (b) and Al-Si alloy sample (c).

diffusing rate that was five times larger than that of the stainless steel. Thus, only the surface thin layer that was heated directly by the plasma jets was molten and the melting pool and heat-affected zone were not clearly observed on the microphotograph of the crosssection (Fig. 2(c)).

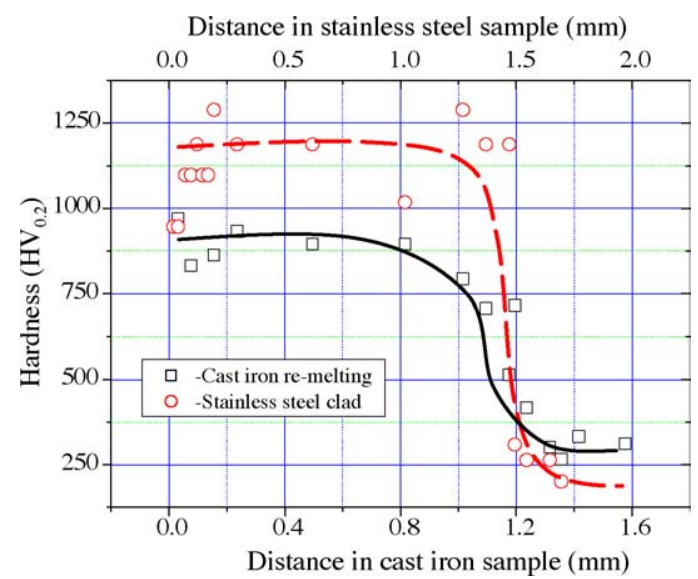

Fig. 3. The hardness profile along the depth direction of the plasma processed layers: the square symbol corresponds to the cast iron sample processed by remelting and the circular symbol to the stainless steel sample processed by cladding. The vertical line 0.0 corresponds to the sample surfaces. 
A typical hardness profile along the depth direction of the heat-affected zones of the cast iron sample is presented in Fig. 3. The hardness in the heat-affected zone reached about $900 \mathrm{HV}_{0.2}$ that is three times that of the substrate. The fact shows that the laminar plasma remelting can produce a non-diluted hardening zone on the cast iron surface. However, evident improvement of the hardness for the stainless steel and Al-Si alloy samples was not observed because they do not have phase change in the corresponding temperature range.

\subsection{Cladding tests}

Fig. 1(d) shows the cladding track of the stainless steel treated by the laminar plasma jets with addition of $\mathrm{Al}_{2} \mathrm{O}_{3}$ ceramic powder. Comparing to the remelting results of the stainless steel (Fig. 1(a)), the cladding trace exhibits a uniform bulging profile. This can be explained as following: during the cladding procedure a portion of the heat energy of the laminar plasma jets had been consumed in heating the ceramic powder, which led to lower temperature of the molten ceramic/ metal mixture and its apparent viscosity sharply increased. Also, injection of the ceramic powder interfered with the flow fields of the plasma gas and reduced the plasma gas speed and pressures acting on the molten liquid. Similar reasoning can be adapted to the explanation of the quite different surface features exhibited by the Al-Si alloy cladding tracks. From Fig. 1(e), it can be seen that the appearance of the cladding track shows the finer surface fluctuation and the dimples appearing on the remelting track surface (Fig. 1(c)) have disappeared.

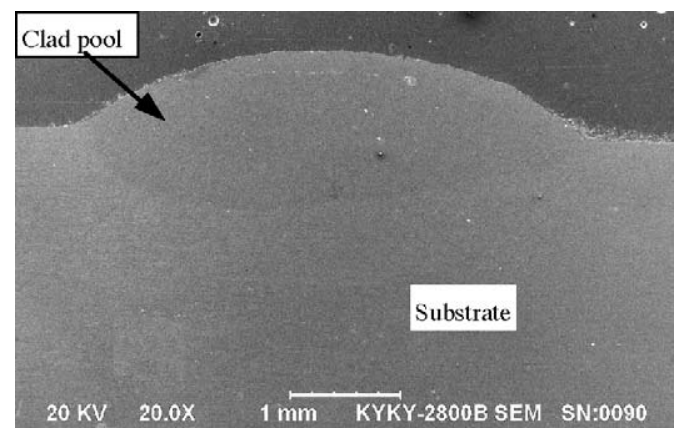

Fig. 4. The microstructure of the cross-section of the clad track of the stainless steel.

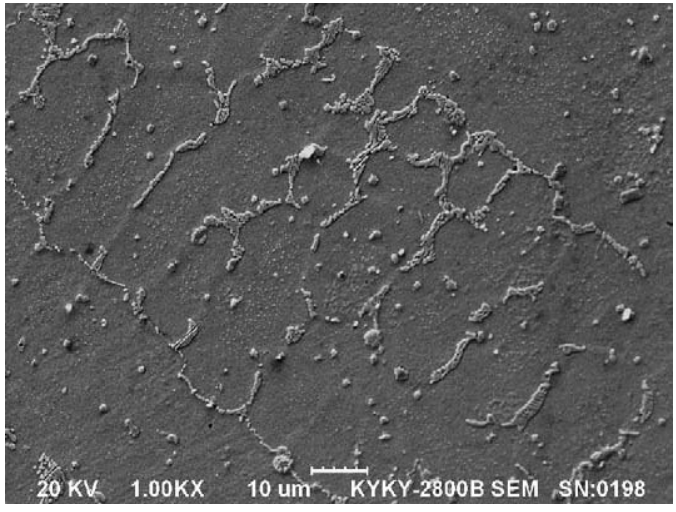

Fig. 5. High magnification SEM metallograph of the cross-section in the clad layer of the stainless steel sample.

Fig. 4 shows an SEM photograph of the cross-section microstructure of the cladding track of the stainless steel, which revealed a good fusion bond between the cladding layer and substrate. No pores and disjunction in the remelting zone were observed, which shows that the laminar plasma cladding technique can produce good cladding layers. An enlarged SEM picture of the cross section is shown in Fig. 5. In the cladding zone the $\mathrm{Al}_{2} \mathrm{O}_{3}$ ceramic phases have segregated out along the grain boundaries and the grain corners, and many discrete ceramic phases have been developed within the grains. This fact was also demonstrated by the results of the EDS line-scan analysis of the $\mathrm{Al}$ element distribution in the clad layer as shown in Fig. 6.

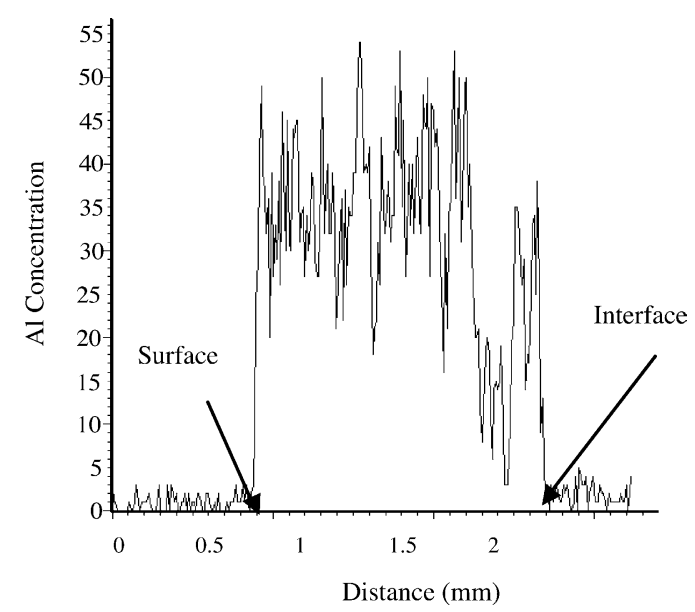

Fig. 6. The result of the EDS line-scan analysis of element $\mathrm{Al}$ in the clad layer in the stainless steel sample. 


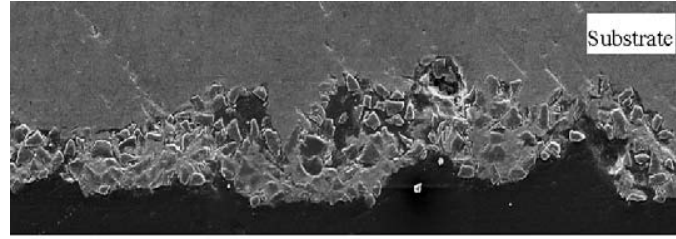

$100 \mu \mathrm{m}$

Fig. 7. SEM cross-section image of the clad layer of the $\mathrm{SiC}$ powder on the Al-Si alloy substrate.

Fig. 7 illustrates the cross-section of the plasmaclad layer of the $\mathrm{Al}-\mathrm{Si}$ alloy with the $\mathrm{SiC}$ ceramic powder. The cladding layer consists of the primary non-molten $\mathrm{SiC}$ particles embedded in the substrate. Because the melting point of the Al-Si alloy is very much lower than that of the $\mathrm{SiC}$ ceramic powder, the $\mathrm{SiC}$ ceramic powder with high melting point of about $3400{ }^{\circ} \mathrm{C}$ exists in its original form in the melting pool. The profile of the EDS line-scan analysis of the Si element distribution across the cladding layer is shown in Fig. 8, which illustrated that concentration of element Si had a sudden increase in the melting pool.

Hardness profile along the depth direction of the clad layer of the stainless steel sample is shown in Fig. 3. Because of the rapid cooling rates of the melting metal, a fine microstructure of the ceramic phases segregated out in the clad layer, which resulted in the high hardness with the average Vicker's hardness number of over $1100 \mathrm{HV}$. Since the poor heat conductivity of the stainless steel reduces the cooling rates and the

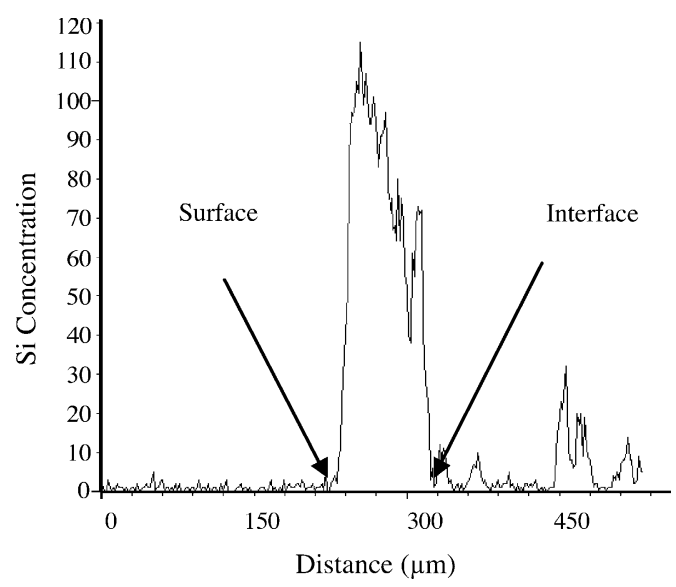

Fig. 8. The result of the EDS line-scan analysis of Si element in the clad layer on the Al-Si alloy substrate. temperature level of the solid, only a very thin heataffected layer between the melting pool and the substrate was formed. Hence, the influence of the plasma cladding on the hardness of the materials was primarily restricted in the cladding layer. For the $\mathrm{Al}-\mathrm{Si}$ alloy, the hardness elevation of the cladding layer was not observed, because a weak joint between the nonmolten $\mathrm{SiC}$ ceramic phase and the $\mathrm{Al}-\mathrm{Si}$ alloy phase had been formed in the cladding processing, and the SiC phase has no strengthening effect on the alloy.

\section{Conclusion}

The current studies show that the laminar plasma technique can be used in the surface modification of metals under certain conditions. The remelting processing studies illustrated that the cast iron surface properties, such as hardness and microstructure can be improved appreciably, but the process is not suitable for stainless steel and Al-Si alloy. The cladding processing studies show that it is suitable in the specific application of the stainless steel with $\mathrm{Al}_{2} \mathrm{O}_{3}$ deposition. The improvement of the microstructure and the hardness of the clad layer were noticeably observed. However, the effects were not satisfactory for $\mathrm{SiC}$ addition to the $\mathrm{Al}-\mathrm{Si}$ alloy. Further results of studies on this subject will be forthcoming. The thermal conductivity of the substrate materials and the solidification speeds are the key factors to the improvement of the surface modified properties.

\section{Acknowledgements}

The National Natural Sciences Foundation of China (Nos. 10275085 and 50336010) supported this work.

\section{References}

[1] A.P. Markwood, R.C. Crafer, Opt. Laser Technol. 37 (2005) 99-115.

[2] L. Shepeleva, B. Medres, W.D. Kaplan, M. Bamberger, A. Weisheit, Surf. Coat. Technol. 125 (2000) 45.

[3] L. Sexton, S. Lavin, G. Byrne, A. Kennedy, J. Mater. Process. Technol. 122 (2002) 63.

[4] Y.P. Kathuria, Surf. Coat. Technol. 132 (2000) 265-269. 
[5] L.J. Li, K. Mazumder, in: K. Mukherjee, J. Mazumder (Eds.), Proceedings of the Laser Processing of Materials, Metallurgical Society of American Institute of Metallurgical Engineers, Warrendale, PA, 1985, p. 35

[6] W.X. Pan, W.H. Zhang, W.H. Zhang, C.K. Wu, Plasma Chem. Plasma Process. 21 (1) (2001) 23.
[7] K. Osaki, O. Fukumasa, A. Kobayashi, Vacuum 59 (2000) 47.

[8] H.M. Krumbhaar, W. Kurz, E. Brener, in: G. Kostorz (Ed.), Phase Transformation in Materials, Wiley/VCH, Weinheim, 2001, pp. 81-170. 